Session 2793

\title{
Internet Based Class Presentations to Enhance Distance Engineering Degree Programs
}

\author{
Hossein Salehfar, John Watson, Arnold Johnson \\ School of Engineering and Mines \\ University of North Dakota \\ Grand Forks, ND 58202 U.S.A
}

\begin{abstract}
In this time of rapidly changing technology, the delivery mechanisms for educational programs are constantly evolving. Distance education has become more readily available, and the nontraditional student now has enhanced opportunities in many academic fields. In 1989 the school of Engineering and Mines (SEM) at the University of North Dakota established a distance education program to deliver Bachelor of Science engineering degrees to employees of participating companies. This program was known as the Corporate Engineering Degree Program and has recently expanded into open enrollments and renamed the Distance Engineering Degree Program (DEDP). Currently the DEDP offers the only ABET (Accreditation Board for Engineering and Technology) accredited undergraduate engineering programs at a distance.
\end{abstract}

The current DEDP delivery format includes videotaped lectures, static Internet Web pages of handouts, e-mail, and on-campus condensed summer laboratories. This delivery format ensures that each distance student receives the exact same content as the on-campus program. Major limitations of the program include the inherent delay in students receiving the videotapes, and the asynchronous problems for faculty handling on-campus and distance students in the same class. To shorten the delay in the lecture delivery times, the authors have tested and examined various ways to utilize the power of the Web to synchronize and to better integrate the DEDP student activities with their on-campus counter parts. This paper presents details, procedures, and demonstrations of delivery methods involving text, video and audio capturing software for a spring 2002 Electrical Engineering course. Additional courses in electrical, mechanical and chemical engineering are being delivered in this format in the 2002/2003 academic year.

Introduction

In 1989, UND's School of Engineering and Mines established a distance education program through Continuing Education to deliver Bachelor of Science engineering degrees to employees of $3 \mathrm{M}$ and later to employees of the member companies of the Corporate Engineering Degree Program (CEDP). In 2001 this program was modified to serve individual students, and it became the Distance Engineering Degree Program (DEDP) delivering chemical, electrical and mechanical engineering courses. To date the program has graduated 8 students, who completed lecture courses via videotape, and laboratories through on-campus summer programs. The program enrollment has risen from 8 in fall 1989 to 77 in fall 2002, and, with the recent change 
to serve individual students and the introduction of a civil engineering program, enrollment is expected to continue to increase. Currently the DEDP is also being considered as a potential supplier of distance engineering courses by overseas educational organizations, such as Academics International in Singapore. In addition to investigating alternative delivery methods for lectures as described in this paper, SEM has a 3 year FIPSE (Fund for Improvement of Post Secondary Education) grant from the U.S. Department of Education to investigate online laboratories to further facilitate distance learning. The DEDP offers the only ABET (Accreditation Board for Engineering and Technology) accredited undergraduate engineering programs at a distance.

The current DEDP delivery format includes videotapes of lectures given to on-campus students, static Internet Web pages of handouts, e-mail, faculty/student correspondence, and on-campus condensed summer laboratories. This delivery format ensures that each distance program has exactly the same content as the on-campus program. One major limitation of the current delivery mode of the DEDP is that it normally takes two (2) to three (3) weeks, sometimes even longer, for the video taped lectures to reach off-campus students. As a result, students enrolled in the DEDP program are at times more than three weeks behind their on-campus peers in submitting the required assignments, projects, and tests. This delay also generates additional load for faculty in terms of grading and advising on-campus and distance students at different points in the course. In general, faculty members consider that under these circumstances a distance student requires $50 \%$ more time and attention than an on-campus student. To shorten the delay in lecture delivery times, the authors have tested and examined various ways to utilize the power of the Web to synchronize and to better integrate the DEDP student activities with their on-campus counter parts. However, in considering online course delivery it was important not to overlook student access, and hence methods investigated must be compatible with minimum Internet access configurations.

One of the delivery methods that is currently being tested by the authors uses a combination of the Mimio ${ }^{\mathrm{TM}}$ text capturing device and Camtasia ${ }^{\mathrm{TM}}$ on-screen video capturing software to dynamically (in real time) capture the text and other in-class visuals along with the accompanying (instructor's) audio ${ }^{1,2}$. The captured audio and video are then streamed over the Web in a RealPlayer ${ }^{\mathrm{TM}}$ or Window Media Player ${ }^{\mathrm{TM}}$ format in either real time or off-line ${ }^{3,4}$. Through this delivery format, the DEDP students have same day access (rather than a one to two week delay) to exactly the same class presentation material as their on-campus peers but with the added advantage of replay. This paper presents some of the details, procedures, and demonstrations of these real-time on-line classes that the authors are investigating, along with the advantages that this delivery method offers.

\section{$\operatorname{Mimio}^{\mathrm{TM}}$ Text Capturing}

Mimio $^{\mathrm{TM}}$ is a device that is designed by Virtual link ${ }^{\mathrm{TM}}$ and it attaches to any whiteboard, or other smooth surfaces, and electronically captures everything that is written or drawn on to the surface into a laptop or a desktop computer file in real time. The device captures text and hand drawings in the same color as written on the board as shown in Figures 1 and 2.

The interactively captured text can be saved on the computer hard drive for instant replay at a later time. At the same time, the captured text can also be saved as a set of graphic snapshots in JPEG, BMP, WMF, EMF, or HTML format. The HTML version of the captured text of lecture 
presentations can be made available to students over the Internet as a set of static web pages as illustrated in the following figures. Figure 3 shows the HTML index page of the notes from one of the class lectures captured by Mimio ${ }^{\mathrm{TM}}$, and Figure 4 presents a sample of a static HTML page of instructor's handwritten material.

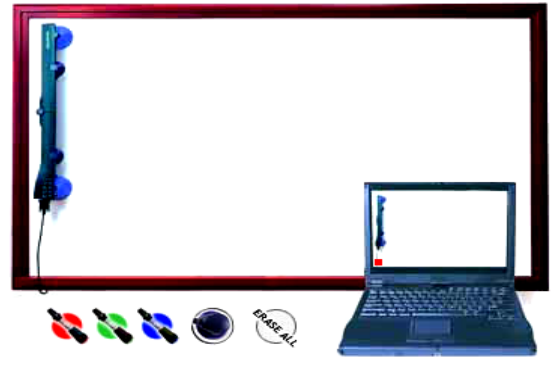

Figure 1: Mimio $^{\mathrm{TM}}$ Capturing Device and Markers ${ }^{1}$.

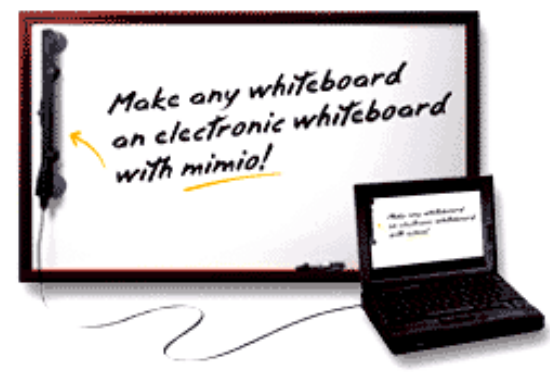

Figure 2: Mimio $^{\mathrm{TM}}$ Captured Text on a Laptop ${ }^{1}$.

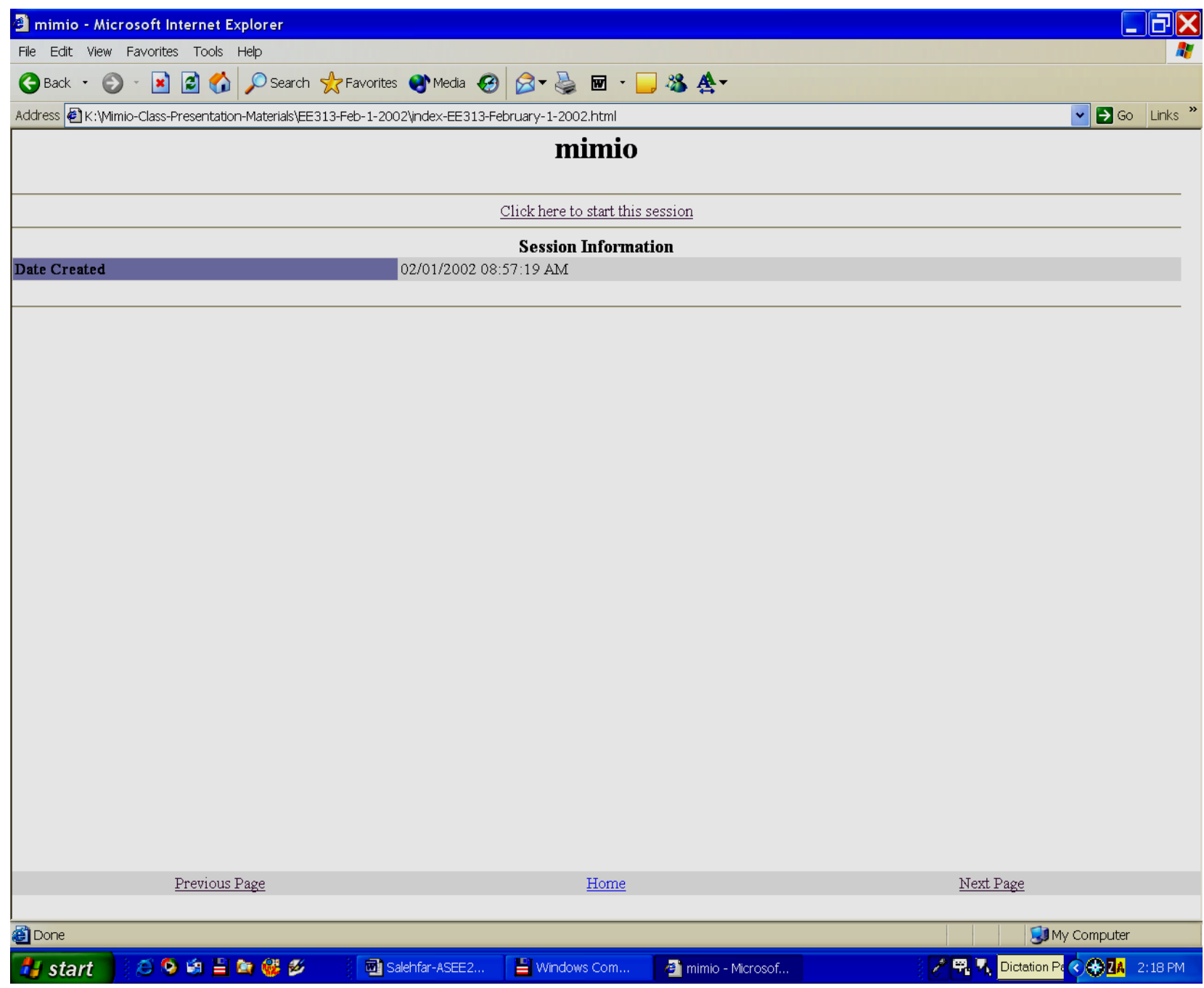

Figure 3: The HTML Index Page of One of the Lecture Notes Created by Mimio

Proceedings of the 2003 American Society for Engineering Education Annual Conference \& Exposition

Copyright (C) 2003, American Society for Engineering Education 


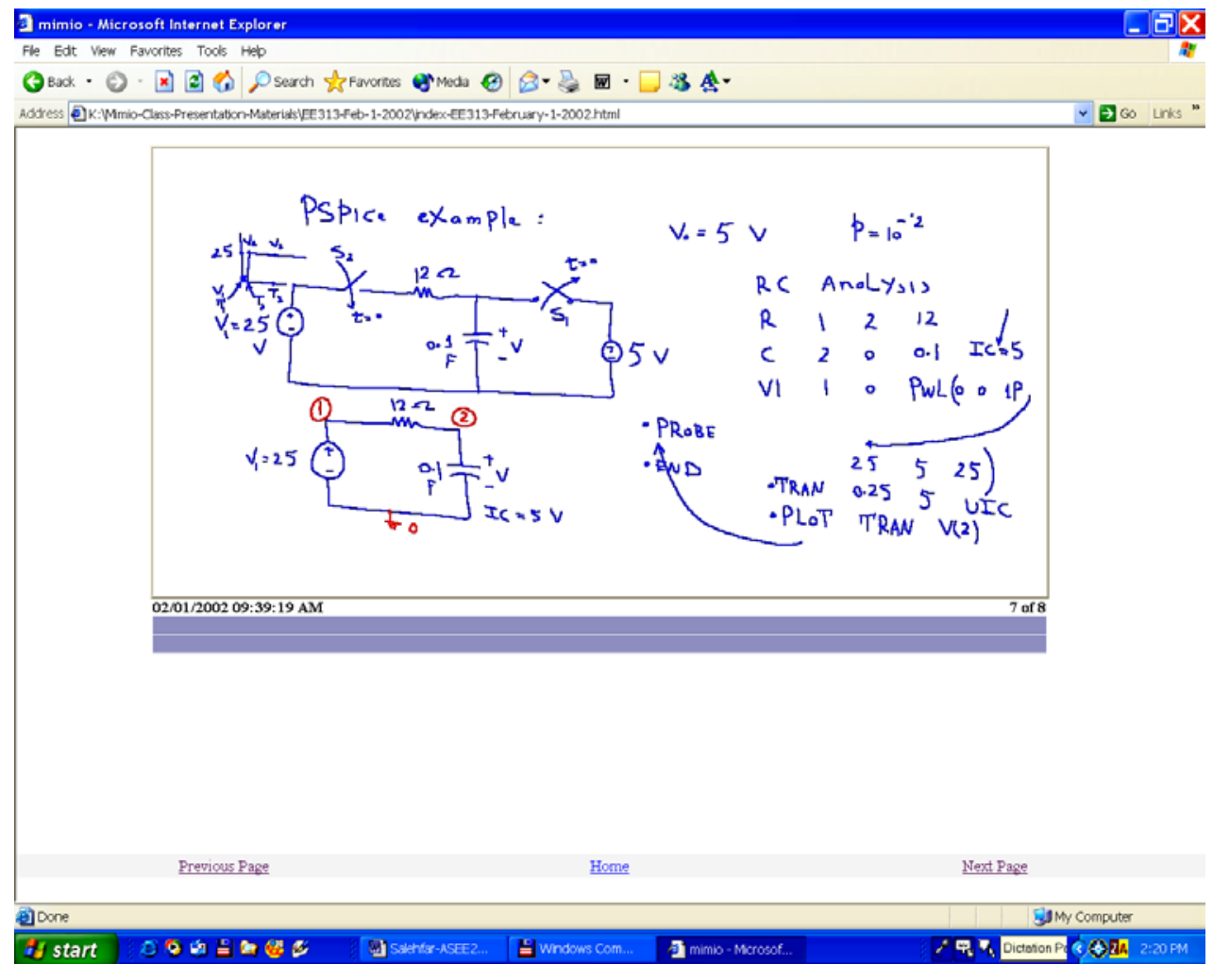

Figure 4: A Static HTML Page of the Lecture Notes Created by Mimio

By clicking on the "Next Page", "Home", or "Previous Page" links of the HTML index page, the user is able to move back and forward through the lecture notes.

Combined with the Mimio's core software, Virtual Link's BoardCast software can also be used to capture and automatically synchronize the voice of the presenter with the captured handwritten text in real time. The combination of handwritten text and voice can be archived on a hard drive or streamed live over the Internet through the freely available RealPlayer ${ }^{\mathrm{TM}}$ or RealOne $^{\mathrm{TM}}$ software as shown in Figure 5. The course material files are easily handled through

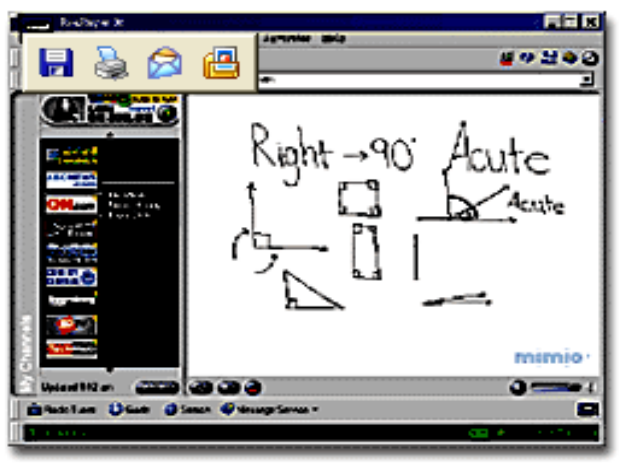

Figure 5: The Mimio BoardCast Through RealPlayer ${ }^{1}$. 
a $56 \mathrm{~K}$ modem with a $200 \mathrm{MHz}$ computer using Windows 95, or higher, and a web browser. A weakness of the Mimio ${ }^{\mathrm{TM}}$ system, however, is that it cannot capture computer-generated visuals such as PowerPoint presentations or videos. The problem is more severe if and when computer based animations or software simulation demonstrations are used in the classroom during lectures. This means that off-campus students will not have equal access to exactly the same classroom materials as their on-campus peers.

To mitigate or eliminate the problem, the authors have successfully combined the Mimio ${ }^{\mathrm{TM}}$ system with a screen video and graphics capturing software to interactively grab voice, handwritten text and drawings, as well as computer generated text, audio, and video. The Camtasia $^{\mathrm{TM}}$ audio and video capturing software by TechSmith ${ }^{\mathrm{TM}}$ works extremely well with the Mimio $^{\mathrm{TM}}$ capturing device. The presentation materials captured by the integrated system of

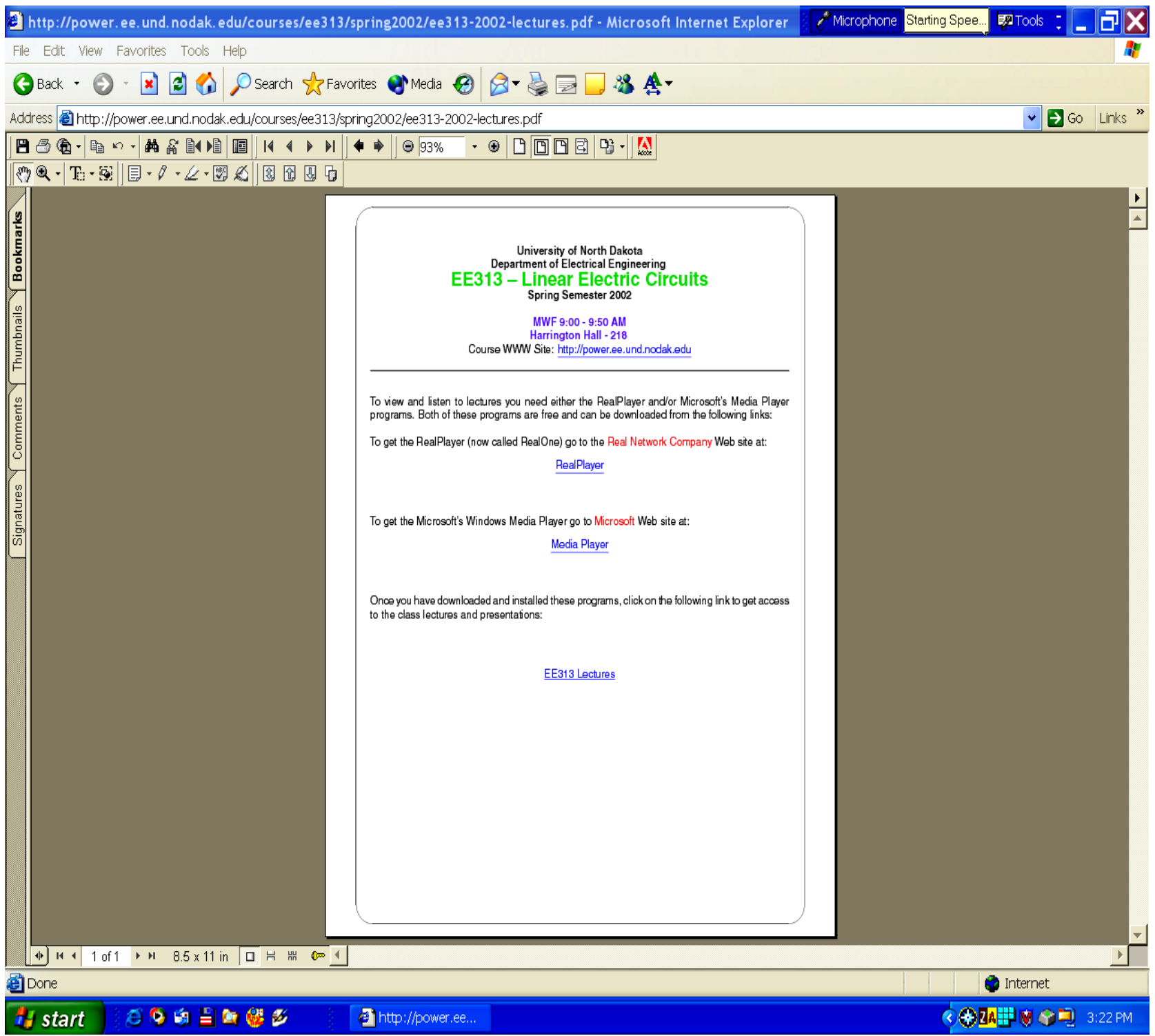

Figure 6: The First Page Linked to the RealOne and Media Player Sites

Proceedings of the 2003 American Society for Engineering Education Annual Conference \& Exposition Copyright (C) 2003, American Society for Engineering Education 
Mimio/Camtasia ${ }^{\mathrm{TM}}$ can be archived or streamed live over the Internet in several different highresolution formats including RealOne ${ }^{\mathrm{TM}}$, Windows Media Player ${ }^{\mathrm{TM}}$, Macromedia Flash, and Apple QuickTime. The figures in the next section of the paper show Internet based snapshots of the materials presented in one of the classes offered and taught to on-campus and off-campus electrical engineering students in the spring of 2002.

\section{On-Line Class Material}

When students connect to an online course's web page, they will see the screen shown in Figure 6. On this page the students are instructed to install the free RealOne ${ }^{\mathrm{TM}}$ and/or Windows Media Player ${ }^{\mathrm{TM}}$ programs by clicking on their corresponding URL links. The students will need to install these programs on their machines only once if they have not done so already. On this same page, a link is provided to the next page where all the lecture materials in RealOne ${ }^{\mathrm{TM}}$ and/or Media Player ${ }^{\mathrm{TM}}$ format are provided as shown in Figure 7.

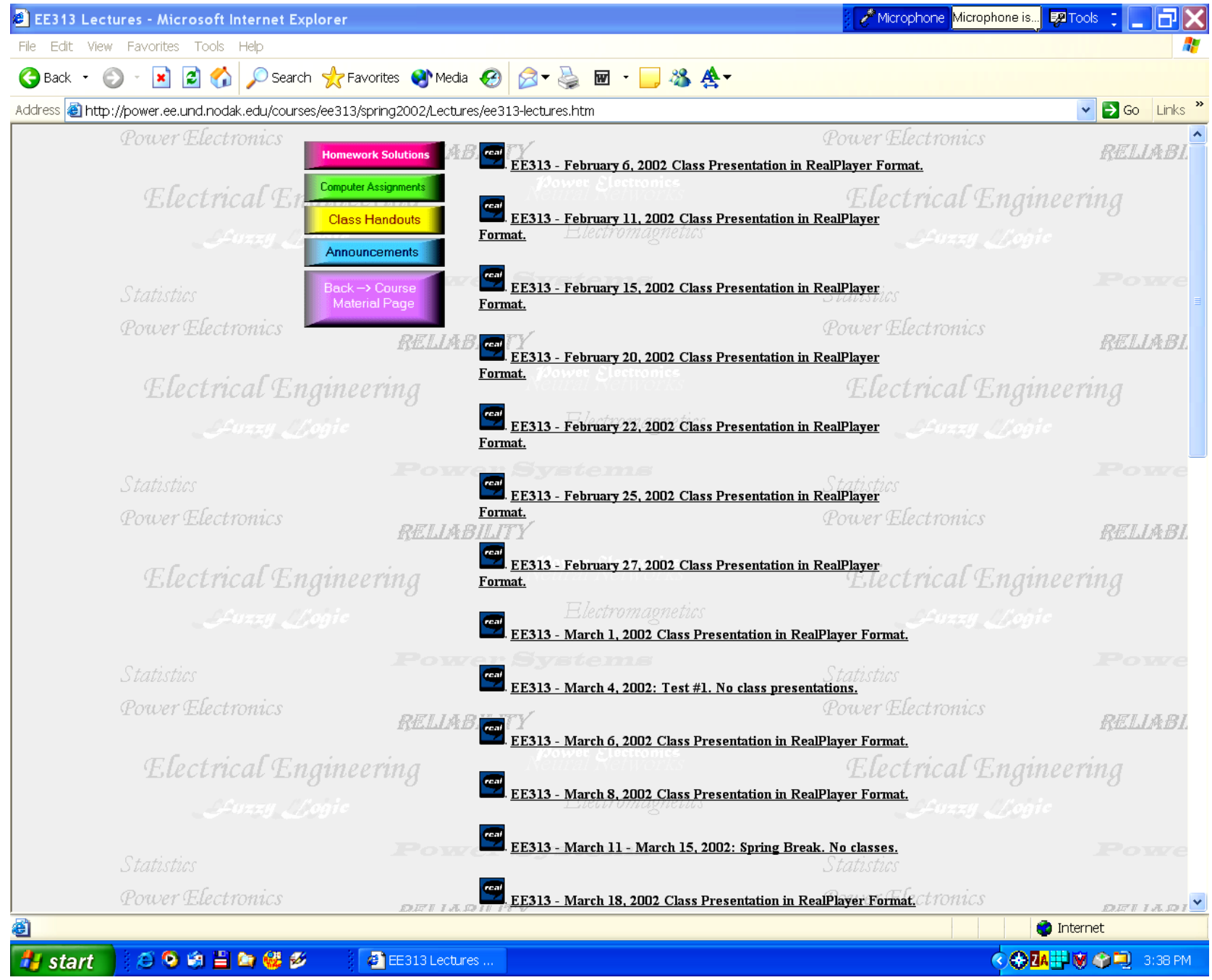

Figure 7: Links to the RealOne ${ }^{\mathrm{TM}}$ and Media Player ${ }^{\mathrm{TM}}$ Lecture Materials 
The next six figures show snapshots of some of the Media Player ${ }^{\mathrm{TM}}$ (Figs. 8 and 9), RealOne ${ }^{\mathrm{TM}}$ (Figs. 10 and 11), Apple Quicktime ${ }^{6}$ (Fig. 12), and Macromedia Flash ${ }^{5}$ (Fig. 13) based lecture materials. In these Figures, typical handwritten equation pages are illustrated for different formats, and Figure 9 shows the output of a PSpice circuit simulation example. A handwritten circuit drawing and its corresponding equations are illustrated in Figure 10, and Figure 11 details the quarter wave symmetry of a waveform during a classroom discussion of Fourier Series. The files are operated very much like a videotape player, and the time into the lecture is displayed together with the total time. An image of the instructor may also be included, and this image can be changed periodically

A survey of students who accessed the spring online course generated very positive comments, and a subsequent survey of all DEDP students indicated that electronic delivery by UND's Continuing Education Department was seen as advantageous. A small sample of the survey responses from DEDP students is included in the Appendix of the paper. Thus, this delivery method clearly has potential to replace the expensive, slow, and cumbersome delivery by videotapes.

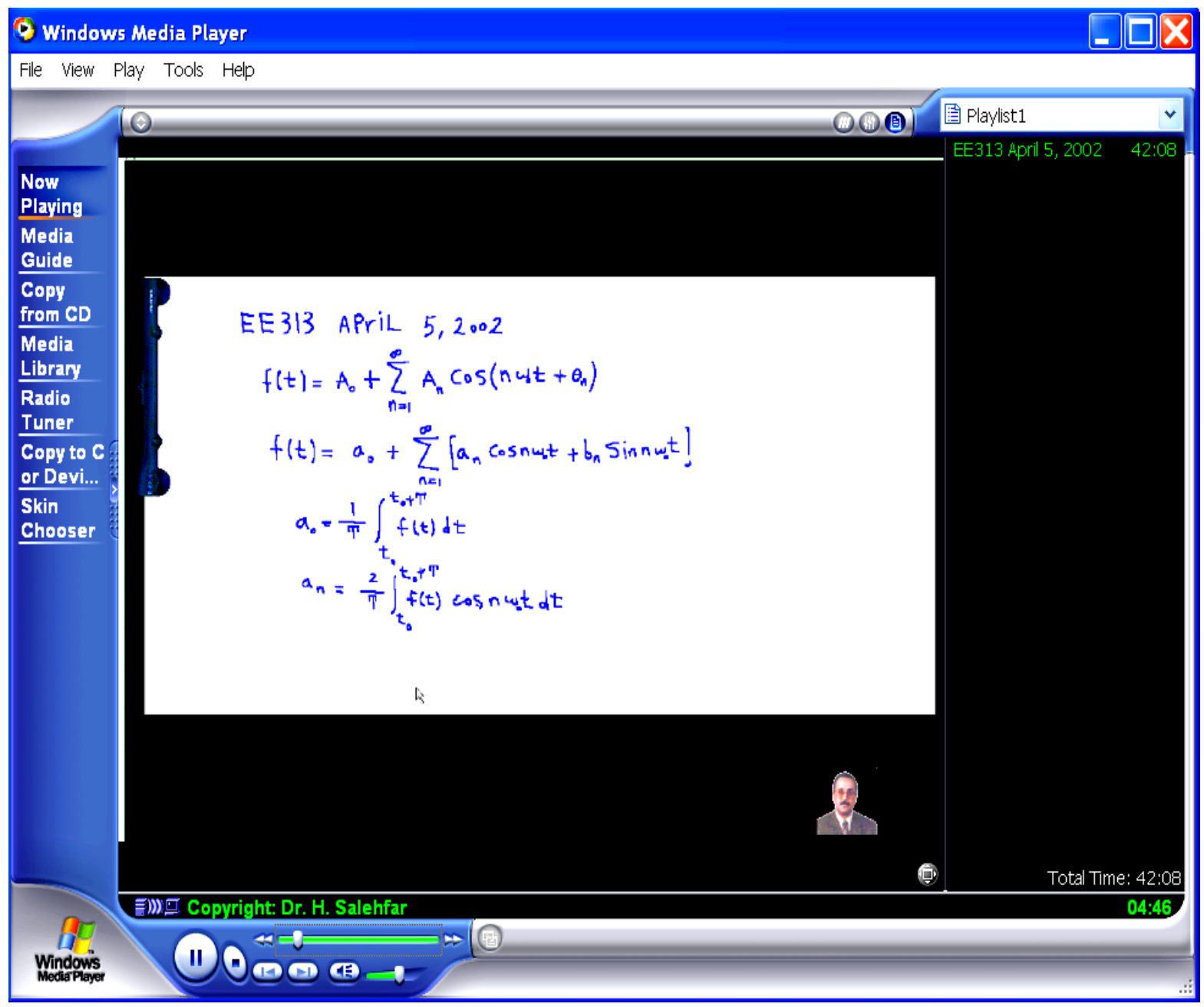

Figure 8: MS Windows Media Player Presentation Snapshot-a 


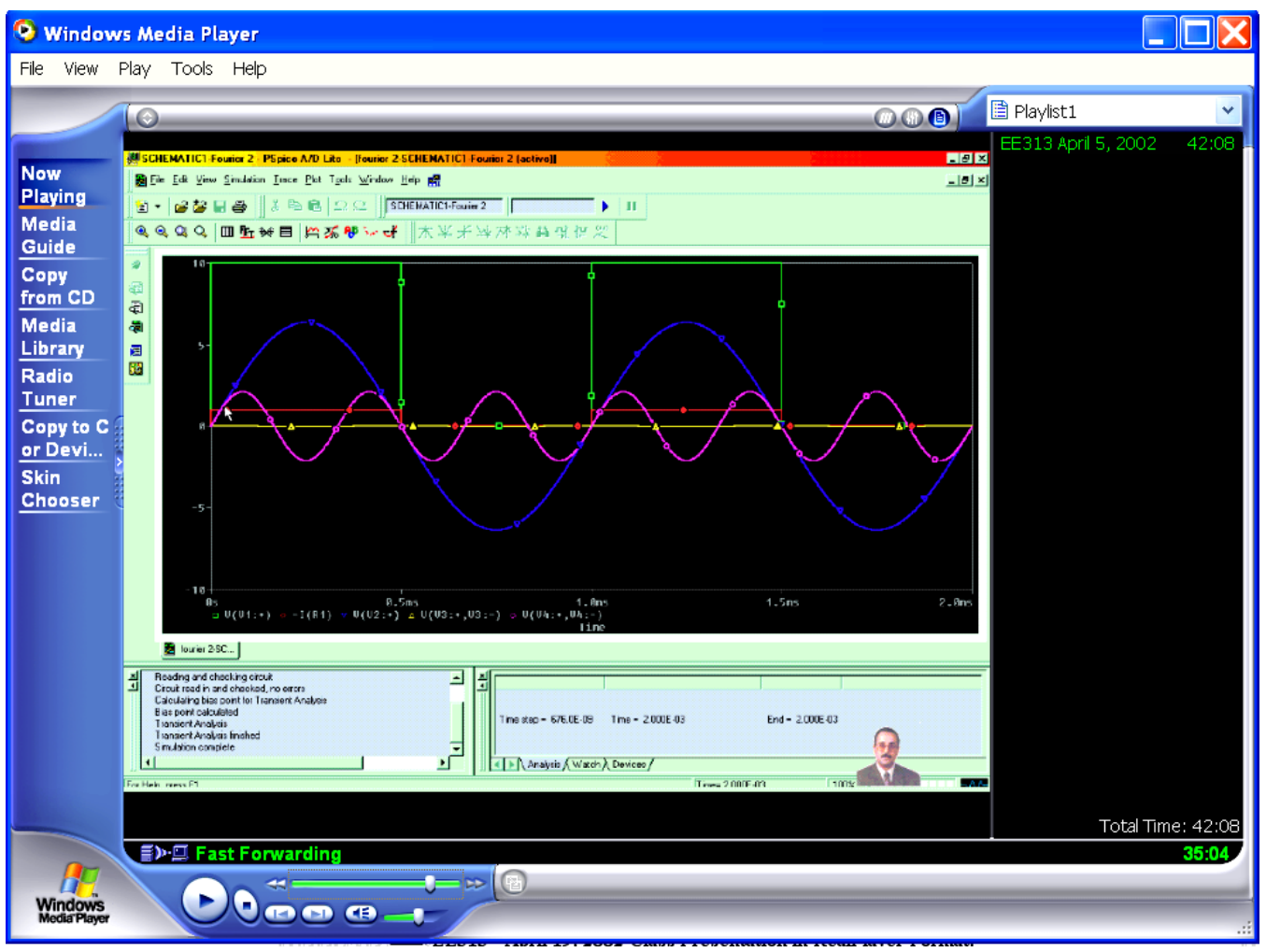

Figure 9: MS Windows Media Player Presentation Snapshot-b

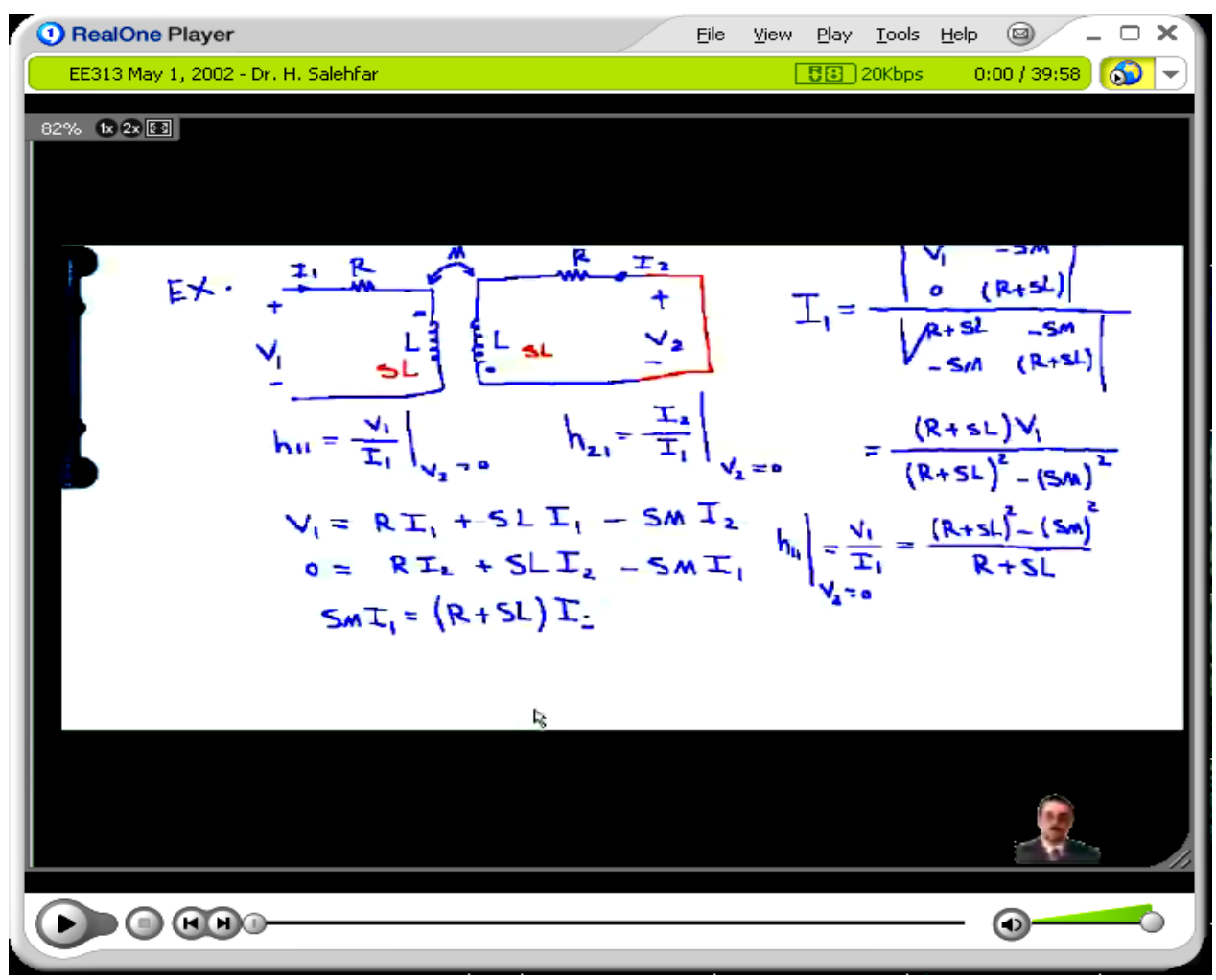

Figure 10: RealOne Player Presentation Snapshot-c

Proceedings of the 2003 American Society for Engineering Education Annual Conference \& Exposition Copyright (C) 2003, American Society for Engineering Education 


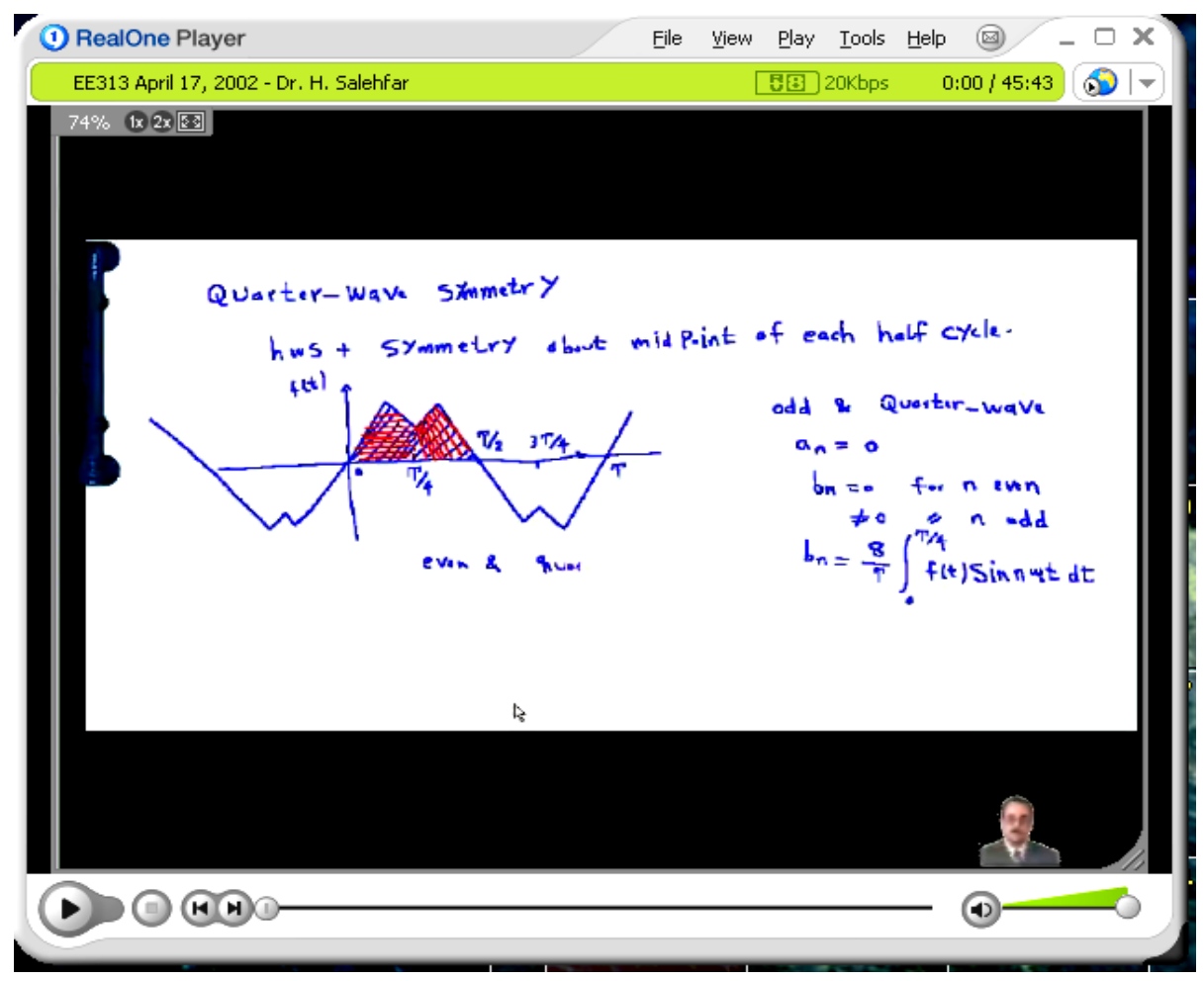

Figure 11: RealOne Player Presentation Snapshot-d

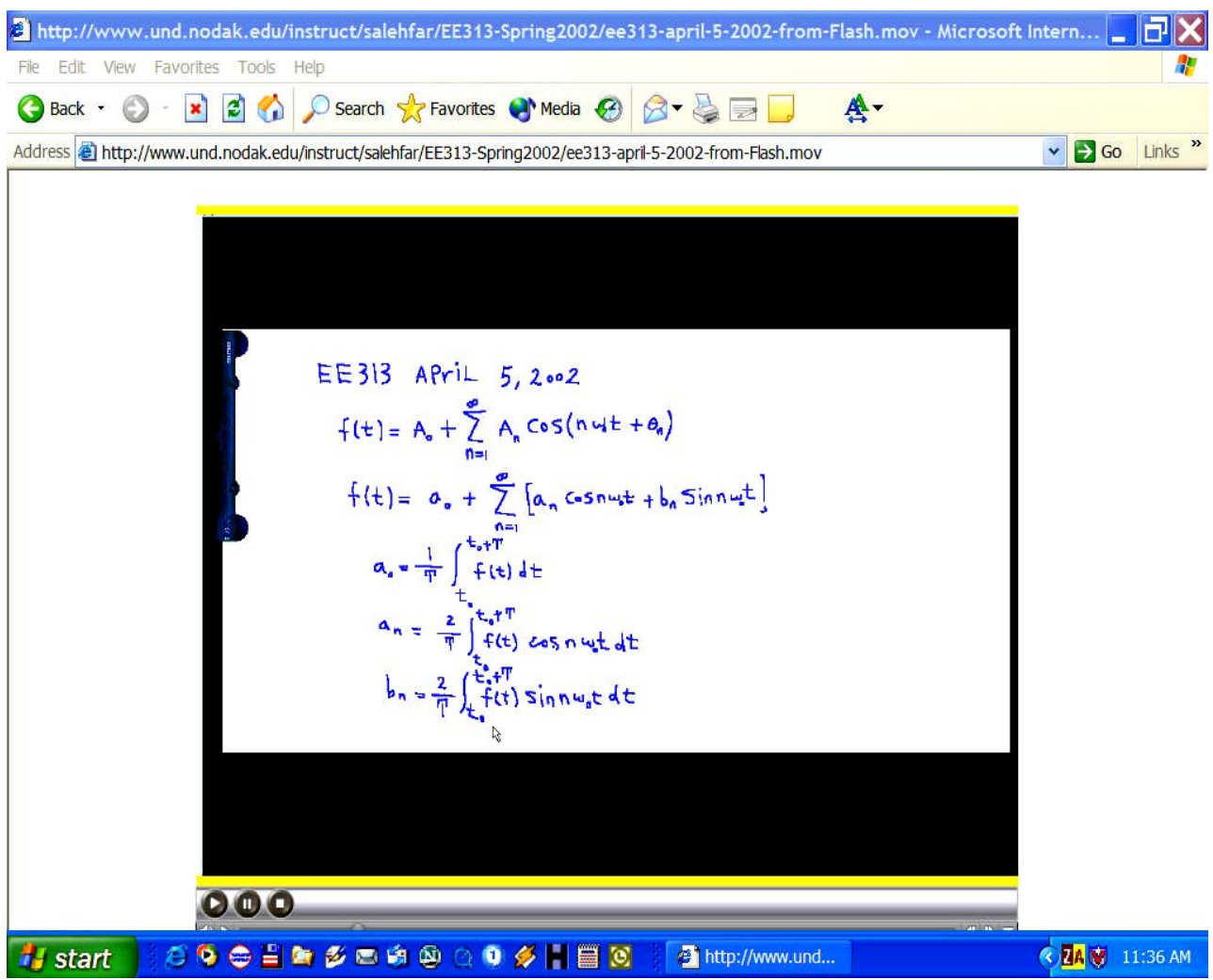

Figure 12: Snapshot of The Apple QuickTime Format Embedded in The IE Browser.

Proceedings of the 2003 American Society for Engineering Education Annual Conference \& Exposition Copyright (C) 2003, American Society for Engineering Education 


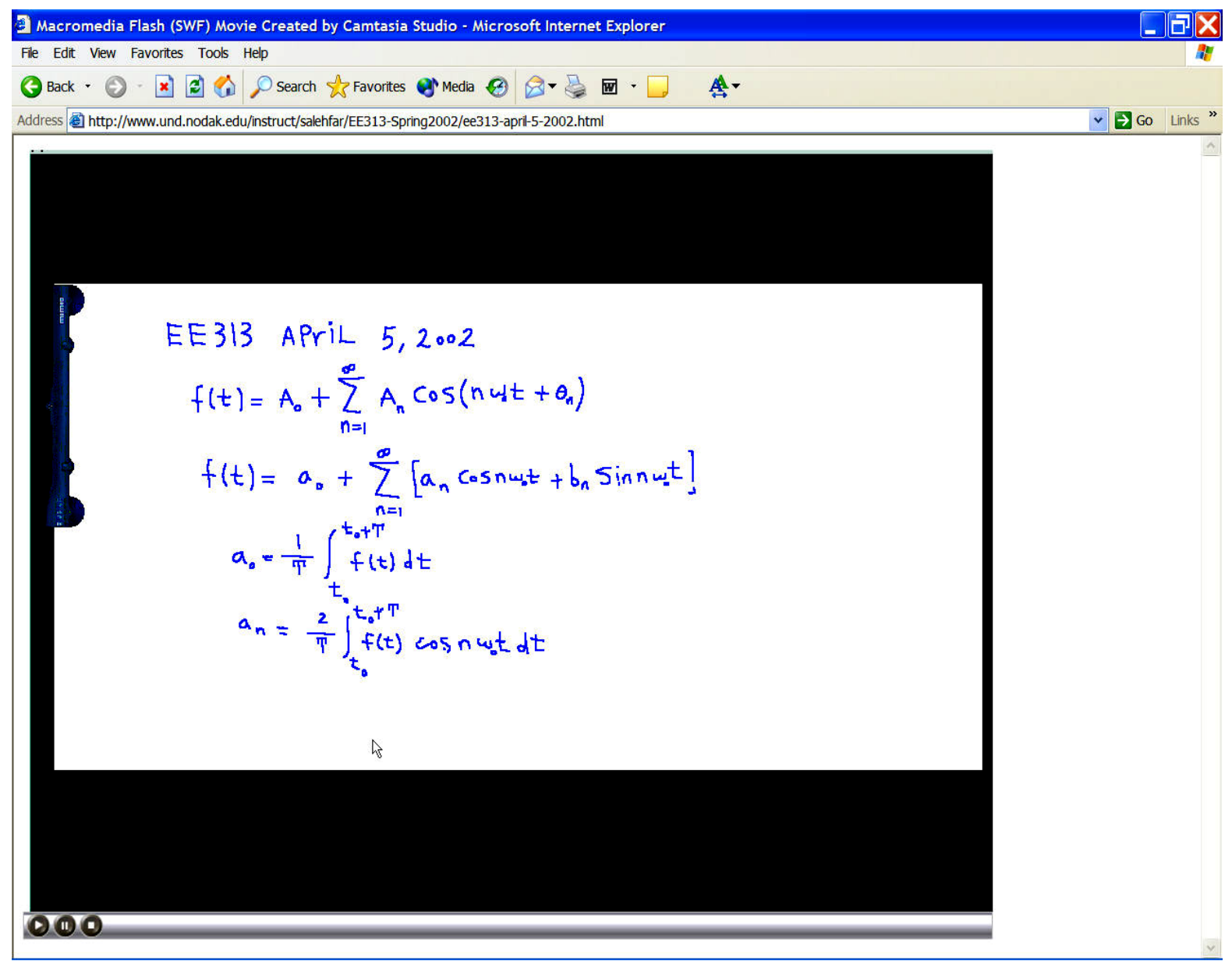

Figure 13: Snapshot of The Macromedia Flash Format Embedded in The IE Browser.

\section{Cost Analysis}

The proposed course delivery tool is an inexpensive and affordable on-line course development and design system that can easily be used by other interested users. The following Table presents a breakdown of the cost of each component and that of the total system. It is assumed that the user already has access to a midrange laptop or desktop computer where the presentations are recorded.

\begin{tabular}{|ll|}
\hline Item & Estimated Cost in \$ \\
Mimio Capturing Device & 550 \\
Camtasia Screen Capture Software & 350 \\
Wireless Microphone System & 50 \\
RealOne Player Software & Free \\
MS Windows Media Player & Free \\
Total & 950 \\
\hline
\end{tabular}

Table 1: Estimated Course Delivery System Cost

Proceedings of the 2003 American Society for Engineering Education Annual Conference \& Exposition Copyright (C) 2003, American Society for Engineering Education 


\section{Conclusions}

The authors are using a combination of the Mimio $^{\mathrm{TM}}$ text-capturing device and Camtasia ${ }^{\mathrm{TM}}$ onscreen video capturing software to dynamically (in real-time) capture the text and other in-class visuals along with the accompanying (instructor's) audio. The captured audio and video are then streamed over the Web in a RealPlayer ${ }^{\mathrm{TM}}$ or Window Media Player ${ }^{\mathrm{TM}}$ format in either real time or off-line. Through this delivery mode, the Distance Engineering Degree Program (DEDP) students of the University of North Dakota have same day access (rather than a one to two week delay) to exactly the same class presentation material as their on-campus peers. Students' reaction to the new delivery mode has been very positive.

The School of Engineering and Mines and the Department of Continuing Education have surveyed all DEDP students, and determined that electronic delivery is acceptable. In addition, the level of access that students have with regard to online material was also established. Further trials are being planned and it is considered that this method of delivering distance courses has great potential.

For an actual demonstration of the method discussed in this paper, the readers are invited to visit the following Web site:

http://power.ee.und.nodak.edu/courses/ee313/spring2002/Lectures/demo/ee313-lectures-demo.htm

\section{References}

1. Virtual Link Corporation, "Mimio," [Online]. Available: http://www.mimio.com/index.shtml.

2. TechSmith Corporation, "Camtasia," [Online]. Available: http://www.techsmith.com.

3. RealNetworks, "RealOne Player," [Online]. Available: http://www.real.com.

4. MicroSoft, "Windows Media Player," [Online]. Available: http://www.microsoft.com/windows/windowsmedia/download/default.asp.

5. Macromedia, "Flash Player," [Online]. Available: http://www.macromedia.com.

6. Apple, “QuickTime Player,” [Online]. Available: http://www.apple.com/quicktime.

\section{Biographies}

HOSSEIN SALEHFAR is currently an Associate Professor of Electrical Engineering at the University of North Dakota. He received his B.S. in Electrical Engineering from the University of Texas at Austin, and his M.S. and $\mathrm{Ph} . \mathrm{D}$. degrees in Electrical Engineering from Texas A\&M University in College Station, Texas. His teaching and research interests currently include fuzzy logic and neural networks application to energy systems, power electronics, and electric drives. Dr. Salehfar is a senior member of the IEEE and the ASEE. 
JOHN WATSON was educated in the U.K, and has worked in industry and academia on four continents over the past 35 years. Prior to becoming the Dean of the School of Engineering and Mines at the University of North Dakota, he spent 20 years at the University of Missouri-Rolla with the last 12 years as Chair of Metallurgical Engineering. His teaching and research interests have included mineral separation processes, computer simulation and control, hydrometallurgical processing of metal wastes, and assessment of student learning.

ARNOLD JOHNSON is the Chair of the Electrical Engineering Department at the University of North Dakota (UND). He has been teaching since 1974 and has been a member of the UND EE Department since 1988. He earned his B.S.E.E. at UND in 1959 and his M.S.E.E. at Iowa State University in 1962. Of the 15 years he spent in industry, five were with Collins Radio (now Rockwell Collins) in their avionics department and the other ten were divided between a small computer firm and an image processing firm.

Appendix

The following is a compilation of a portion of the survey responses received from DEDP students who had accessed the on-line course described in the paper.

\section{Online Survey Results- 11/12/2002 Student Responses}

\section{Advantages of Online Delivery}

"I would prefer to download them to my computer rather than run them from Internet. I participated in the trial run for EE313 in the Spring of 2002 semester and the biggest problem I had was I would get booted off the internet while watching the lecture. If that problem could be eliminated I think it would be much better than videotapes!"

"No disadvantages. If investing in a $\$ 40 \mathrm{~K}$ degree, a $\$ 1500$ computer system and $\$ 40 /$ month broadband is not significant cost. File size no longer an issue with broadband and size of hard drives. Stanford uses this method for EE masters degree, it works very well."

"Would no longer have to return the tapes, and no worry of receiving broken ones.

"The fact that tuition costs would be reduced is a major factor for me as well as being able to finish a course at the same time as on campus students is a huge advantage for me personally. I hope this takes affect as soon as possible, possibly for the winter 2003 term (next term).

"Being able to read the material and having charts, tables and graphs available without waiting to have them sent in the mail. 
"CD's would be better than videotape from the standpoint of expensive and bulky packaging... My recommendation is to try it for one semester as a field trial and get the students' feedback before committing to this method.

"I am in favor of online courses. As an IBM employee much of our on the job training is done this way. This method of delivery is the trend and is the direction that technology is moving."

"Availability to view courses at work or home without needing a special room or equipment to study other than computer."

"With this feature, it would be possible to access the files from places outside the home."

"I think the Internet would be the way to go or at least burning lectures on CDs instead of using videos. I am sure the quality would improve immensely. I am sure there will be some up front cost to the university but in the long run it will be worth it. Burning the lecture on CD would give better quality. With today's technology all computers have DVD player installed or can be purchased."

"Better clarity of information. Clearer sound- better pictures- maybe better technical aspects leading to better understanding of the material. Hopefully future ability to interact with classroom discussion."

"Though I think the course work via the Internet would be nice, the video delivery is still a good method for me. If anything, a current video taping of the day's class that could be transmitted (streamed asynchronous) to my computer each evening would be the best. I don't know how well the white board and audio tape approach will work."

"I currently use a laptop that I bought 1 1/2 yrs ago specifically so I'd have a portable classroom that I could take with me both to on-campus labs and also on trips so I can do homework while I'm away on business. It affords me portable access to email."

"Hopefully, better quality of presentation and immediate access to course material."

\section{Disadvantages of Online Delivery}

"Need to have files that will work with Macintosh, \& one other disadvantage of having a $56 \mathrm{~K}$ modem is that the class cannot be fast forwarded or reversed very fast. I like to refer back to the classes sometimes, but I have to spend a lot of time finding what I need when the class is online.

"The biggest objection to online Internet access is that possible obstruction to getting access (e.g. Phone lines busy, cable modem access is busy or down equipment failure). Downloading would be quicker and cause less congestion on the delivery end. 
"I don't really see an advantage. The disadvantages outweigh any benefit. CDs would be better than straight from the Internet. You really have to have a lot of RAM and a fast Internet server to make stream video work. It is better to have a hard copy such as CD or videotape."

"I doubt that there would be a reduction in course costs..."

"The only real advantage I would foresee would be a lower tuition. I like the "live" feeling of the videotape, and don't think the audio files would give you the same feel. Also, I think that simulated labs through the computer would not be as beneficial as the real thing. Thanks for considering my input." 